\title{
Mimarlıkta Kitsch ve Estetik Deneyim: Bosphorus City
}

\author{
Emel CANTÜRK AKYILDIZ ${ }^{1}$
}

\section{Öz}

Günümüzde küreselleşmenin etkisiyle, her alanda olduğu gibi, mimarlık üretiminde de piyasa değeri egemen olmakta; beğeni ve anlamın ortaya çıkış süreci giderek yapaylaşmaktadır. Güncel mimarlık üretiminde özellikle dikkat çeken olgulardan birisi de kitsch olgusudur. Giderek daha fazla mimari ürün ve kentsel çevre kullanıcısına gerçek bir deneyim sunmak yerine, tarihsel ve mekânsal referansları bağlamlarından kopararak kullanmakta, bu 'tanıdık' biçim kurgusu aracılığıyla kendini tanımlı kılarak, geniş kitlelerin beğenisine hitap etmektedir. Kitsch olgusuyla ilişkili olarak tanımlanabilecek bu tür bir mimari üretimin izleri İstanbul'da da kolaylıkla bulunabilir. Örneğin, İstanbul'un en tipik özelliklerden birisi olan 'İstanbul Boğazı' imgesini, ait olduğu mekânsal bağlamdan kopararak, sahte bir imge yaratan Bosphorus City, bu tür bir mimari üretimin son yıllarda uygulanmış olan çarpıcı örneklerindendir. $\mathrm{Bu}$ kapsamda, bu çalışmanın amacı kitsch olgusunu bütün boyutlarıyla ele alarak kavramsallaştırmak ve kitsch bir yapılı çevre olarak Bosphorus City projesinin, 'beğeni', 'anlam', 'tüketim kültürü' ve 'ideoloji' boyutlarıyla ilişkisini ve özneye sunduğu 'estetik deneyim'i tartışmaktır. Çalışmada kitsch kavramı, öznenin eleştirel mesafesini ortadan kaldıran bir olgu olarak sorunsallaştırılmaktadır. Gerçeklikten kaçma arzusundaki kitsch tüketicisi, kitsch mimari ve kentsel çevrelerin içinde, giderek gerçek bir kentsel-mimari deneyimin sunduğu zorluklar ve sorumluluklarla yüzleşme becerisini kaybetme tehlikesiyle karşı karşıyadır. Bu bağlamda, mimari ve kentsel çevrelerin 'estetik' kalitesinin tartışmaya açılması önem kazanmaktadır.

Anahtar Kelimeler: Kitsch, anlam, tüketim kültürü, estetik deneyim, Bosphorus City.

\section{Kitsch and Aesthetical Experience in Architecture: Bosphorus City}

\begin{abstract}
\footnotetext{
1 Maltepe Üniversitesi Mimarlık ve Tasarım Fakültesi, Mimarlık (İngilizce) Bölümü

* İlgili yazar/Corresponding author: emel.canturk@gmail.com

Gönderim Tarihi: 17.07.2020

Kabul Tarihi: 11.12.2020
}

Today, within the effect of globalization, the process of emergence of taste and meaning in architectural production is becoming increasingly artificial. One of the phenomena that attracts particular attention in current architectural production is the phenomenon of kitsch. Instead of providing a real experience to the users, today more and more architectural products use historical and spatial references by detaching them from their context, and appeal to the taste of masses by defining themselves through this 'familiar' form. Traces of such an architectural production, which can be defined in relation to the kitsch phenomenon, can easily be found in Istanbul. For example, the Bosphorus City project, which creates a false image by detaching the image of 'Bosphorus' from the spatial context it belongs to, is one of the striking examples of such an architectural production. The aim of this study is to conceptualize the phenomenon of kitsch, and to discuss its relation with concepts of 'meaning', 'consumer culture' and 'aesthetical experience' through the Bosphorus City. In the study, the concept of kitsch is problematized as a phenomenon that eliminates the critical distance of the user. The kitsch consumer, who desires to escape from reality, 
faces the threat of losing his/her ability to face the challenges and responsibilities of a real urban-architectural experience within kitsch environments. In this context, it is important to open the 'aesthetic' quality of architectural and urban environments to discussion.

Keywords: Kitsch, meaning, consumption culture, aesthetical experience, Bosphorus City.

\section{GiRiş}

Ingilizce bir kavram olan kitsch'in etimolojisi hakkında farklı görüşler olmakla birlikte, bazı yazarlar tarafından İngilizcedeki sketch (eskiz) sözcüğünden türediği, yaygın olarak ise Almancadaki werkitschen (ucuza yapmak), ya da yine Almanca bir sözcük olan kitschen'den (sokaktan çöp toplamak) geldiği kabul edilmektedir (Dorfles, 1969, s. 3). Etimolojisinin de çağrıştırdığı gibi kitsch kavramı ana hatlarıyla, yozlaştırma, bayağılaştırma, kopyalama, sahtelik, estetik uygunsuzluk gibi kavramlara gönderme yapar. Amerikalı sanat eleştirmeni Greenberg, 1939 tarihinde yayınlanan Avangard ve Kitsch makalesinde, kitsch'i "sentetik bir sanat" (Greenberg, 1961, s. 15) olarak tanımlamakta ve aşağı kültürle özdeşleştirmektedir (Greenberg, 1961, s. 9). Türk Dil Kurumu'nun Güzel Sanatlar Sözlüğü'nde ise kavram, "özenti ürün” şeklinde tanımlanmaktadır.

Calinescu'nun (2010, s. 261) ifadesiyle; "Bir şeyi kitsch olarak adlandırmak birçok durumda onu zevksiz, itici, hatta iğrenç olarak reddetmenin bir yoludur. Fakat kitsch, estetik üretimin ya da estetik kabulün geniş alanıyla tümden bağlantısız nesne ve durumlara uygulanamaz". Calinescu (2010), kullanım bağlamlarını ne kadar sınıflandırırsak sınıflandıralım kitsch'in hep bir estetik yetersizlik fikrini içerdiğini ve bu tür bir yetersizliğin de biçimsel nitelikleri, kültürel içerik ya da niyetleriyle uyumsuz nesnelerde bulunduğunu yazmaktadır. Bu açıdan bakıldığında, estetiği ifade etmek için ortaya konan görüşler, kitsch kavramının tam karşıtında yer alıyor gibi görünse de kitsch, estetik olmayan olarak algılanmamalıdır; tam aksine kitsch'i başlı başına ayrı bir estetik kategori (Broch, 1969; Kulka, 2002) veya estetik kalitenin farklı bir türü olarak (Tanyeli, 1990) tanımlamak daha doğru olacaktır.

Diğer yandan kitsch, ekonomik gelişme ile de doğrudan bağlantılıdır; hatta kapitalist düzenin bir uzantısı olarak da görülebilir. Bu açıdan, estetik bir olgu olmasının yanı sıra, kitsch'in aynı zamanda tüketim kültürü ile ilişkili sosyolojik bir olgu olduğu da görülür. Kitsch'in tüketim kültürü tarafından ideolojik olarak yönlendirildiği görüşü, Adorno (2003), Greenberg (1961), Baudrillard (1997) ve Calinescu (2010) gibi pek çok kültür ve sanat eleştirmeni tarafından paylaşılmaktadır. Kitsch, süreksizliklerle dolu modern dünyada, modern insanın gerçeklikten kaçma isteğini karşılar; istenmeyen problemleri güvenli ve steril bir dünyayla maskeler (Calinescu, 2010; Kundera, 1986; Atkinson, 2007; Broch, 1969). Günümüzde, kolay anlaşılır, kolay tüketilir olan ve yenisine olan talebi çabuklaştıran kitsch, sanattan başlayarak giderek gündelik hayatın her alanına yayılmış ve mimarlıkta da bir tür beğeni ifadesi, belli bir kültürün temsili olarak yerini bulmuştur.

Kitsch'i estetik bir olgu olarak kavramsallaştırmak gerektiğinde üzerinde durulması gereken temel kavramların en önemlileri, biçim, beğeni ve anlam olarak sıralanabilir. Anlam ve beğeni kitsch olgusunun tanımlanmasında önemli bir yer tutar, çünkü kitsch, bir tür beğeni ifadesidir ve anlamlı gözükmektedir. Sosyolojik bir olgu olarak kitsch ele alındığında ise, tüketim kültürü, ideoloji ve kitle iletişim araçları önemli konular olarak öne çıkmaktadır. 
$\mathrm{Bu}$ çalışmada kitsch olgusu, estetik ve sosyolojik boyutlarıyla ele alınarak kavramsallaştırılmakta ve kitsch mimari nesnelerin/yapılı çevrelerin özneye sunduğu 'estetik deneyim', bu tür mimari çevrelerin son zamanlardaki en çarpıcı örneklerinden Bosphorus City projesi üzerinden tartışmaya açılmaktadır. Bu tartışmaların temelinde ise, kitsch'in, öznenin eleştirel mesafesini ortadan kaldıran bir olgu olarak sorunsallaştırılması yer almaktadır. Mimari/kentsel çevrelerin giderek kullanıcısıyla eleştirel mesafesinin kapandığı ve gerçek bir 'estetik deneyim' sunmaktan yoksun olduğu günümüzde, eleştirel bir bakış açısının geliştirilmesi ve mimarlıkta 'estetik deneyim' olgusunun tartışmaya açılmasının önem kazandığı düşünülmektedir.

\section{BOSPHORUS CITY ÜZERINDEN MIMARI ÜRETIMDE 'KITSCH' OLGUSUNUN TARTIŞILMASI}

'İstanbul'un İkinci Boğazı' olarak promosyonu yapılan, tasarımına 2007 yılında başlanan ve 2011 yılında inşaatı sona eren Bosphorus City projesi İstanbul Boğazı temalı bir konut projesi olarak Küçükçekmece'de $246.000 \mathrm{~m}^{2}$ lik bir alanda, Sinpaş GYO tarafından hayata geçirilmiştir. Etap etap tamamlanan proje 2000 konutluk ve 10.000 kişilik bir kapasiteye sahiptir.

Proje alanının İstanbul Boğazı ile hiçbir ilişkisi olmamasına rağmen, projenin promosyonu İstanbul'un ikinci boğazı olarak yapılmakta ve tüketiciye "Boğaz'ın benzersiz güzelliği ile ayrıcalıklı bir yaşam" şeklinde sunulmaktadır. Proje kapsamında, İstanbul'un karakteristik kentsel öğelerinin kullanıldığı, İstanbul Boğazı temalı bir yerleşim alanı tasarlanmış ve hayata geçirilmiştir (Şekil 1). Projenin resmî sitesinde ${ }^{2}$, projenin tasarımında İstanbul'la kurulan analoji açıkça belirtilmektedir: "İstanbul Boğazı'nın topografik özellikleriyle özdeş, boylamasına uzanan arazinin elverişli topografyası; 7 tepeli şehir İstanbul'un, titizlikle projelendirilen 2. Boğazı Bosphorus City için ilham kaynağı oldu" (url-1).

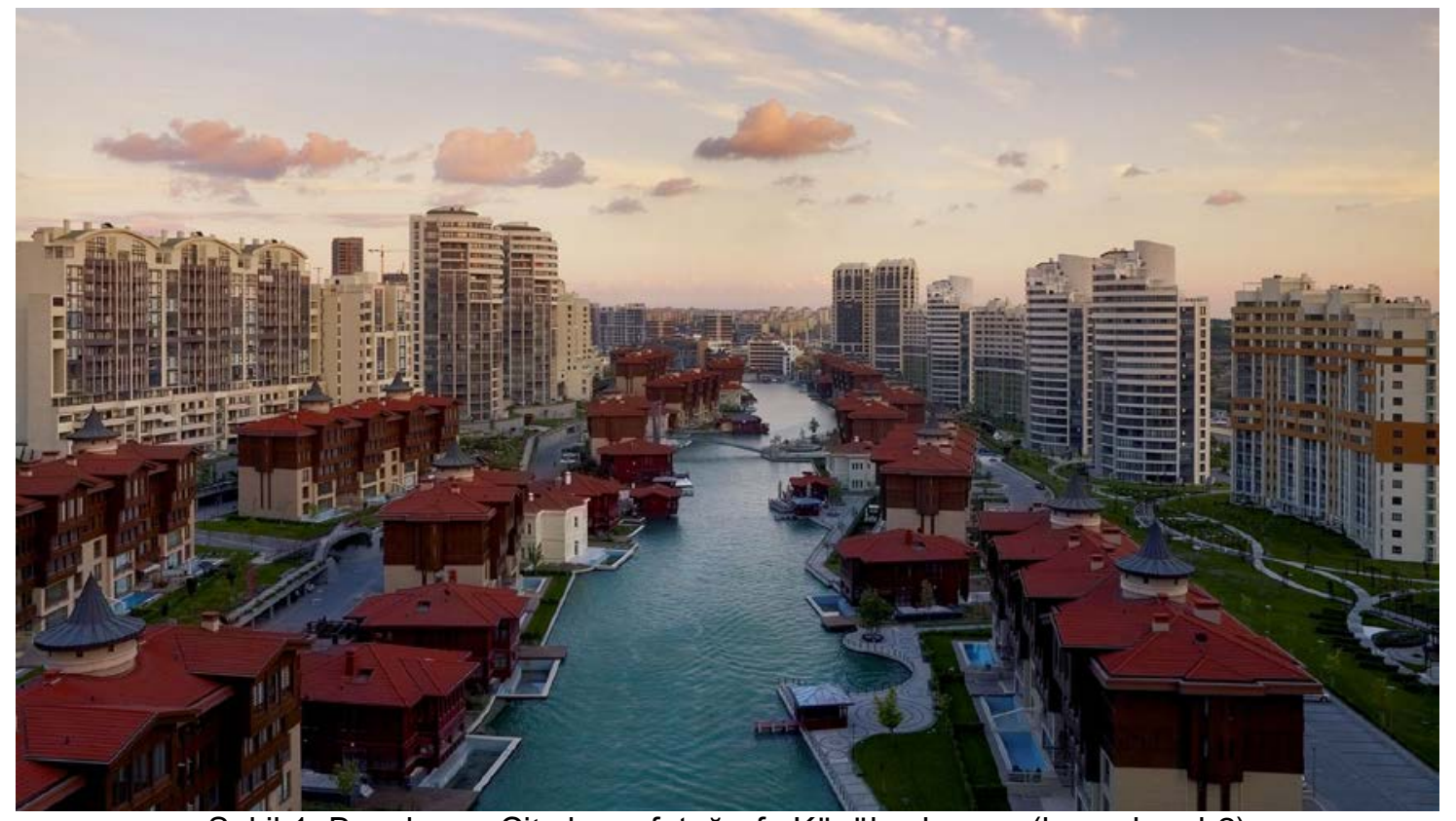

Şekil 1. Bosphorus City hava fotoğrafı, Küçükçekmece (kaynak: url-2)

\footnotetext{
${ }^{2}$ Projenin resmi tanıtım sitesi olan http://www.bosphoruscity.com.tr adresine erişim kapanmıştır. Resimi tanıtım sitesindeki tanıtım yazılarından bir bölümü https://bosphoruscity.wordpress.com/ adresinde yer almaktadır.
} 
Projenin mimari tasarımını üstlenen Evrenol Architects'in ortağı Mehpare Evrenol ise bir röportajında ilk günden itibaren projenin isminden rahatsız olduklarını, kullanılan isimlerin projenin önüne geçtiğini belirtmiştir (url-3). Mimarların açıklamasına göre, "Bosphorus City'nin tasarımındaki en önemli girdi, zengin açık alan kullanımı sağlayan 'su' ve 'yeşil'in iç içe geçtiği rekreasyon alanlarıdır." Ayrıca, "geleneksel sivil mimarinin özellikli örneklerinin plan ve cephe düzleminde modernize edilerek projeye özgün bir nitelik kazandırdığını" savunmaktadırlar (url-2).

Ancak gerçekleştirilen proje incelendiğinde, projenin 'özgünlük' kavramından oldukça uzak olduğu görülmektedir. Projede 1,5 m derinliğinde bir yapay su kanalı oluşturulmuş ve kanalın etrafında, Bebek Parkı, İstinye Koyu, Yeniköy, Paşabahçe, Emirgan, Çınaraltı, Kanlıca, Kandilli ve Çengelköy gibi İstanbul'un semtleri ve karakteristik öğeleri kullanılmıştır. Bazı durumlarda mekânlar fiziksel benzerlik göstermeyip sadece semt isimleri ve yaşam tarzları kullanılırken (Şekil 2), bazı durumlarda ise Çengelköy'deki tarihi yalılar ya da Boğaz Köprüsü örneklerinde olduğu gibi, kentin karakteristik öğeleri ‘biçimsel özellikleri oldukları gibi korunarak' kullanılmıştır (Şekil 3).
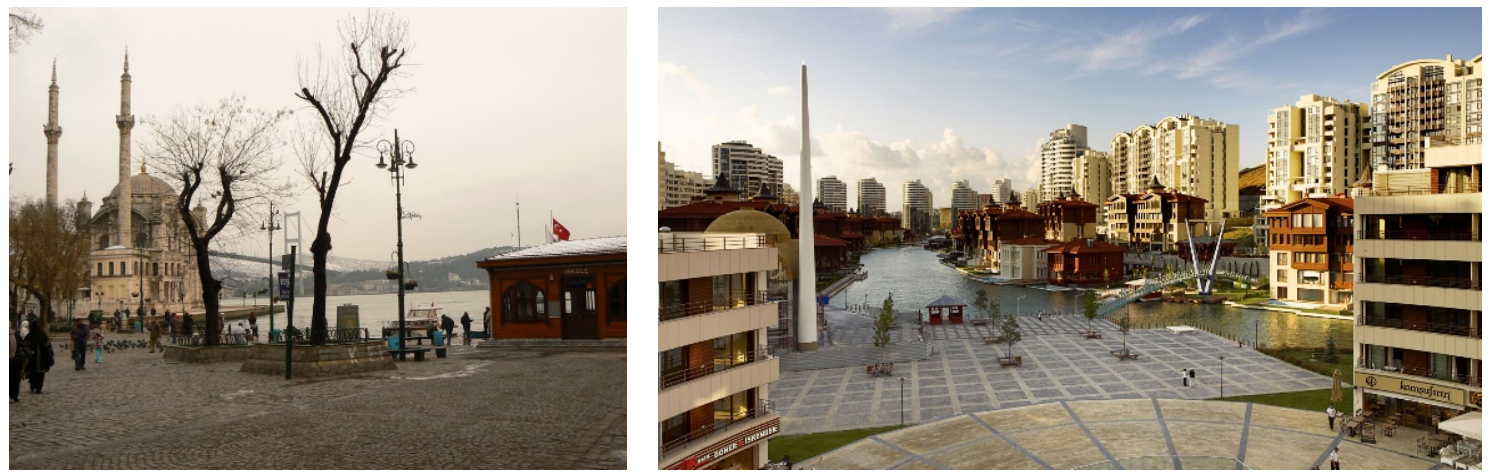

Şekil 2. (a) Ortaköy Meydanı (kaynak: anonim) (b) Bosphorus City’de camisi ve 'Boğaz Köprüsü’yle Ortaköy Meydanı (kaynak: url-2)

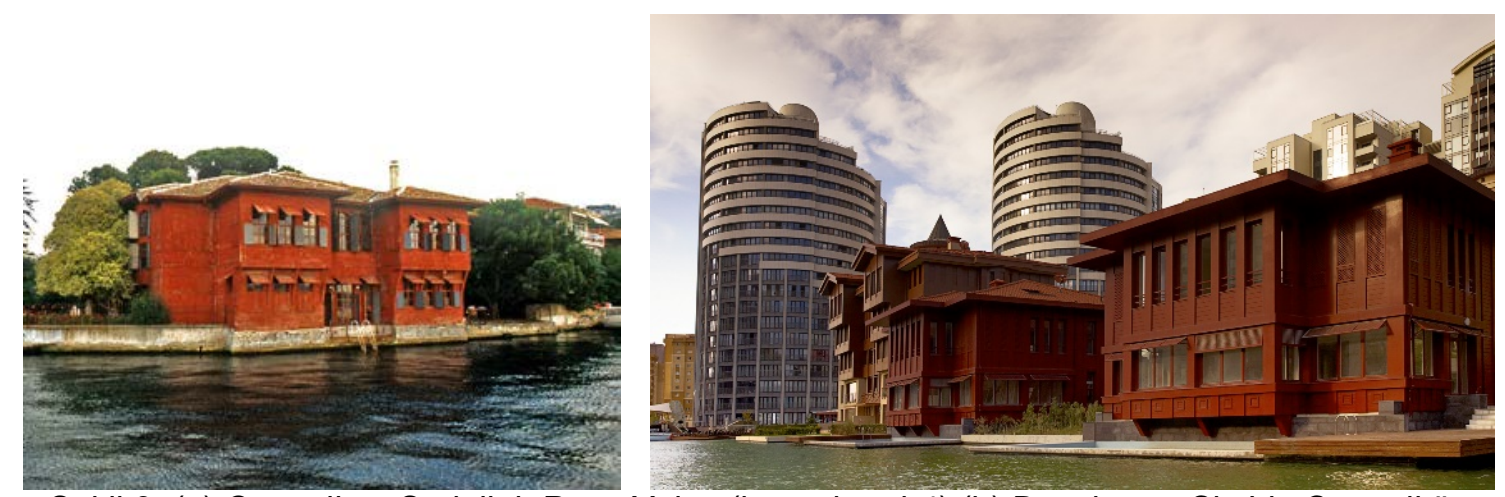

Şekil 3. (a) Çengelköy Sadullah Paşa Yalısı (kaynak: url-4) (b) Bosphorus City'de Çengelköy yalıları (kaynak: url-2)

Proje, İstanbul'un en karakteristik özelliği olan Boğaz'ını ve sahil şeridindeki tarihi yapılarını kullanarak sahte ve pazarlanabilir bir İstanbul görünümü sunmaktadır. İçerik ile biçimin arasındaki kopukluk, anlamın ve içeriğin nesneyle eş anlamlı olmaması, mimari öğelerin bağlamlarından koparılarak taklit edilmesi ve imgelerin ait oldukları gerçeklikle kullanıldıkları gerçeklik arasında sahte bir ilişki kurması gibi özellikleri dolayısıyla proje kitsch'in bütün gerekliliklerini yerine getirmektedir. 


\subsection{Estetik bir olgu olarak 'kitsch': biçim, anlamın oluşumu ve beğeni}

Estetik bir olgu olarak kitsch, bir beğeni ifadesi olarak ortaya çıkar, bu bakımdan anlamın oluşumuyla ve beğeni kavramıyla ilişkilidir. Kulka (2002), kitsch'i kötü bir estetik kategori olarak tanımlarken, yaptığı gözlemlerden biri kitsch'in kitleler için güçlü bir çekiciliği olduğudur. Kitsch'in kitleler için bu kadar çekici olmasının nedeni ise, kitsch nesnelerin içeriklerinin geniş kitleler tarafından anlaşılır olması, evrensel konulardan oluşması ve yoğun bir duygusallık taşımasıdır (Kulka, 2002, s. 19-20). Bu bakımdan kitsch'in alımlanması zahmetsiz ve kolaydır, bu yüzden de çekicidir.

Mimarlıkta da kitsch'in bir beğeni ifadesi olarak ortaya çıkmasında ve insanların kitsch nesneleri beğenmesinde, kitsch'in kendini kolayca ve açıkça ortaya koyan yapısı ve Scruton'ın (1979) belirttiği gibi mimari nesnenin diğer sanat formlarındaki nesnelere oranla kamusal olması ve gündelik hayatın içerisinde yer alması önemli rol oynar. Gündelik hayatın içinde yer alan ve istesek de istemesek de yüzleşmek zorunda olduğumuz mimarlık nesnelerini, anlamlandırmaya intiyaç duyarız. Colquhoun (1988), mimarlığın diğer sanat disiplinlerinden ayırıcı iki önemli özelliği üstünde durur. Birincisi, mimarlığın ekonomik ve politik kaynaklarla sıkı sıkıya ilişkili olmasıdır. Bu yüzden de mimarın genel beğeniden bağımsız, özerk olarak hareket etmesi oldukça zordur. İkincisi ise, mimari ürünlerin 'dalma' (contemplation) içinde değil, 'dikkati dağınıklığı' (distraction) içinde algılanmasıdır (Colquhoun, 1988, s. 8).

Mimarlık nesnesinin gündelik hayatın içinde yer alması ve algılanma biçimlerinin de farklılaşması dolayısıyla, insanların, verilmek istenen mesajı son derece açık ve net veren mimari ürünleri algılaması, anlamlandırması, onlara anlam yüklemesi daha kolay olur. Rapoport (1990, s. 14), "insanların içinde bulundukları çevreye onu birçok açıdan incelemeden ve değerlendirmeden çok daha önce, onun hakkında genel ve etkin bir şekilde, ilk algıladıkları anda tepki gösterdiklerini ve insanların kentsel alanları, çevresel alanları ve yapısal formları onu anlamlandırdıkları için sevdiğini” yazmaktadır. İşte bu yüzden kitsch de insanların belleklerindeki yapısal formları prototipler olarak kullanır, algılanması kolaydır, çünkü tanıdıktır.

Kitsch, toplumun belleğinde bir anlamı oluşan ve meşrulaşan öğeleri kullanıcıların beğenisine sunar. Objeler kendi özgün formlarının salt varlığı yanında, bir geçmişi olan duyguları harekete geçirirler. Bu geçmiş materyale bağlanır ve çevremizde bulunan imajlar, insanların karar vermesinde etkin rol oynarlar (Rapoport, 1990, s.14). Bosphorus City projesi de İstanbul'un karakteristik yapılarını ve özelliklerini, örneğin geleneksel Türk evi motiflerini, Boğaz Köprüsü'nü, hatta boğazın kendisi gibi simge değeri olan ve toplumun belleğinde yer edinen öğeleri kullanır (Şekil 4,5 ve 6). İstanbul'un bildik ve tanıdık öğelerinin tekrarlanması, kullanıcıların bu kent parçasını anlamlandırmalarını kolaylaştıı. Kitlelerce kitsch'in bir beğeniye cevap vermesinin sebebi, biçim kurgusuyla kendini tanımlı kılan kitsch'in bildik ve tanıdık olmasıdır denebilir. 

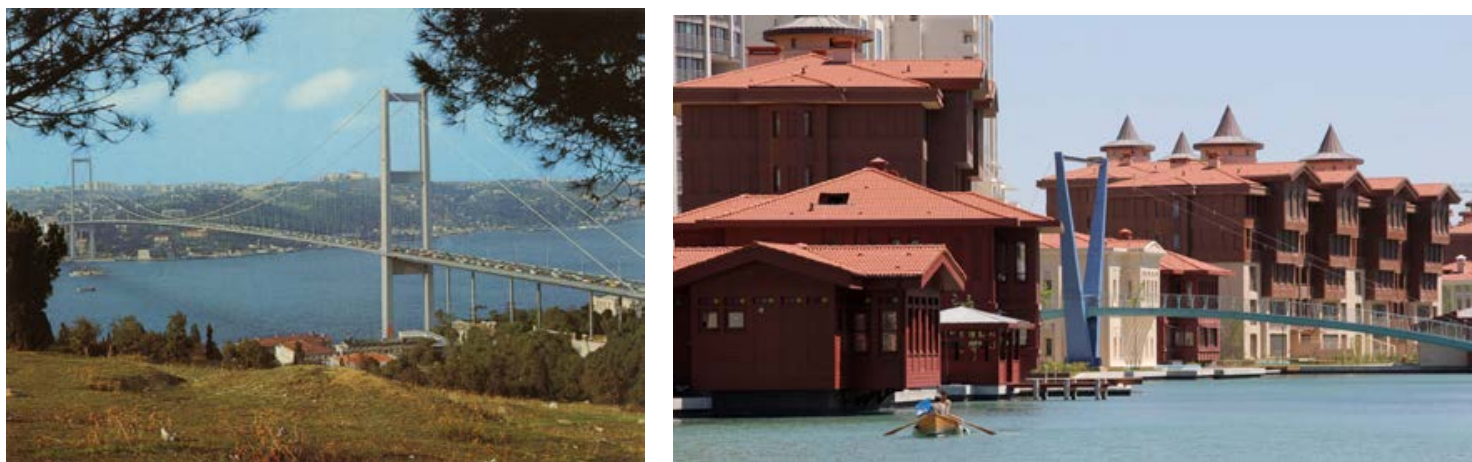

Şekil 4. (a) Boğaz Köprüsü (kaynak: url-5) (b) Bosphorus City Boğaz Köprüsü (kaynak: url-6)
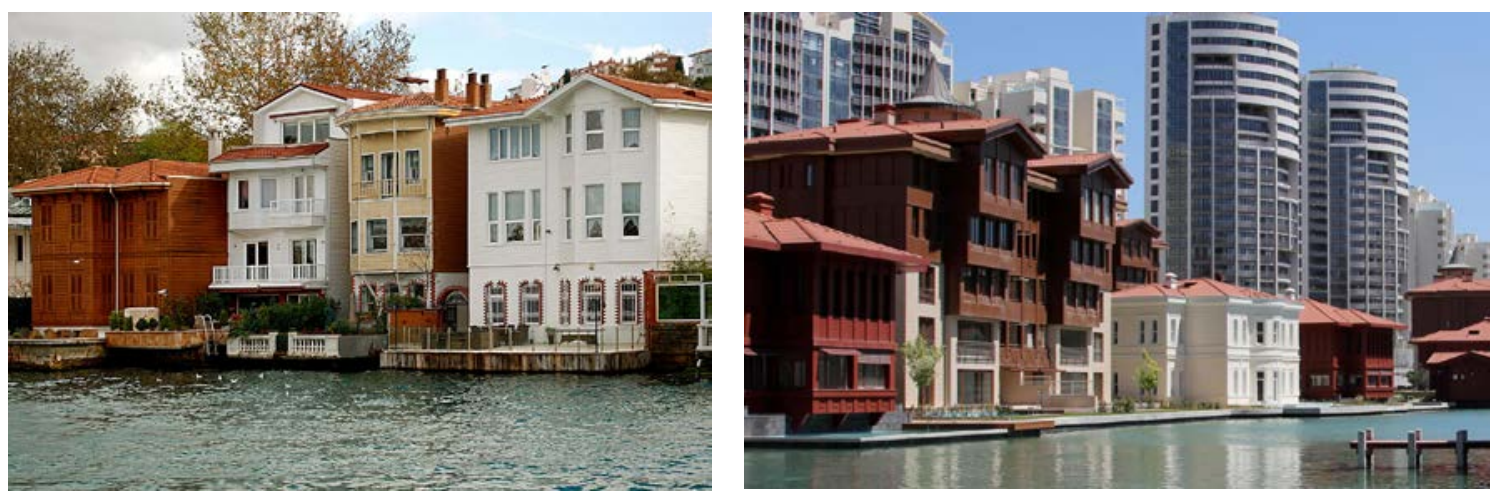

Şekil 5. (a) Kanlıca sahil şeridinde yalılar (kaynak: url-7) (b) Bosphorus City yalı apartmanları (kaynak: url-2)
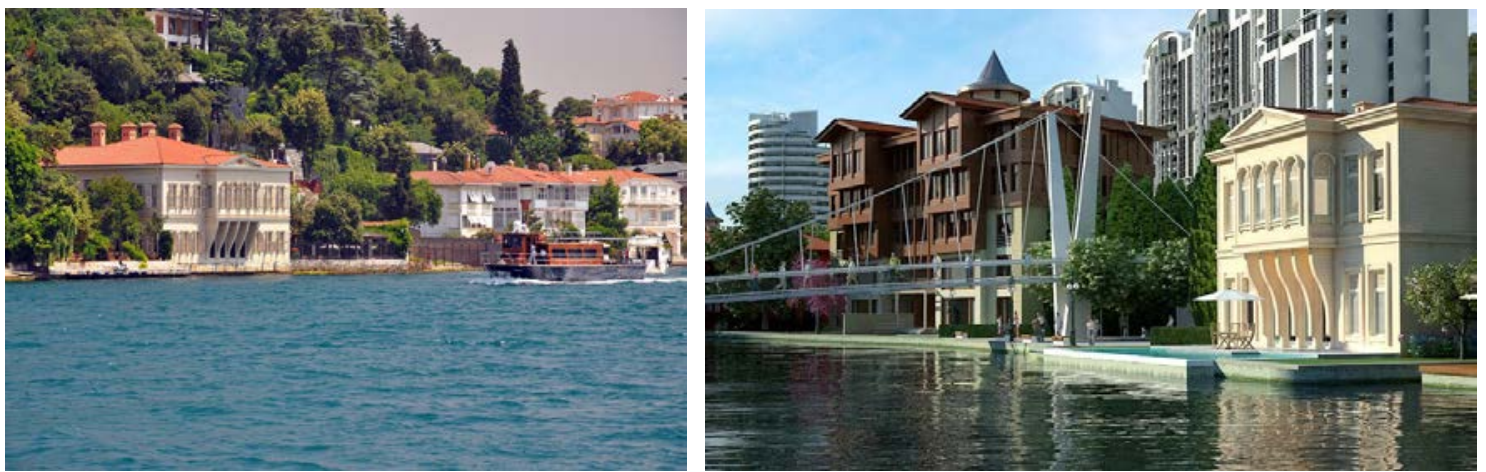

Şekil 6. (a) Zarif Mustafa Paşa Yalısı (url-8) (b) Bosphorus City'den bir yalı (url-9)

Calinescu (2010), kitsch'in gerçekliğin yerine klişeler koyduğunu ve bir takım duygusal intiyaçlardan beslendiğini yazmaktadır. Broch'a (1969, s. 73) göre, "kitsch belirli geleneklerin hala geçerli olduğu tarihin idiline bir kaçıştan başka bir şey olamaz. Kitsch bu nostaljiyi gerçek kılmanın en basit ve doğrudan yoludur." Ancak, Kundera'nın da (1986) belirttiği gibi, kitsch, toplumsal olarak paylaşılabilen duygulara gönderme yapmaktadır. "O halde, kitsch alışılmamış bir durumdan yola çıkamaz; kişilerin belleklerine kazımış oldukları temel imgelerden türemek zorundadır" (Kundera, 1986, s. 258).

Algılamanın temelinde görsellik olduğundan, mimari nesnenin en temel öğesi, aynı zamanda onu anlamanın en temel bileşeni de biçimdir. Bu yüzden kitsch nesne kendisini 'biçim' yoluyla etkili kılar. Kitsch genellikle tarihin belli bir dönemine veya belli bir yere atıfta bulunan bir imgenin ait olduğu tarihsel ve mekânsal bağlam ile kullanıldığı tarihsel ve mekânsal bağlam arasında sahte bir ilişki kurar. Bosphorus City 
örneğinde olduğu gibi, içerik ve anlam nesneyle eş zamanlı değildir, biçim ile anlam arasında çarpık bir ilişki vardır. Projede kullanılan öğeler tarihsel ve yerel bağlamlarından koparılarak, 'ödünç alma' üzerine kurulu bir gerçeklik anlayışı oluşturulmuştur.

Bu yüzden Calinescu (2010), kitsch'i yalan söylemenin kendine özgü bir estetik biçimi olarak tanımlar. Ona göre "kitsch kavramı açık bir şekilde taklit, kalpazanlık, kandırma ve kendi kendini kandırma estetiği diyebileceğimiz bir şeyi merkeze almaktadır" (Calinescu, 2010, s. 255). Bosphorus City'de anlamlarından, işlevlerinden, yerle ve tarihle olan ilişkilerinden koparılarak yeniden üretilen vapur iskeleleri bu duruma iyi bir örnek teşkil eder (Şekil 7).

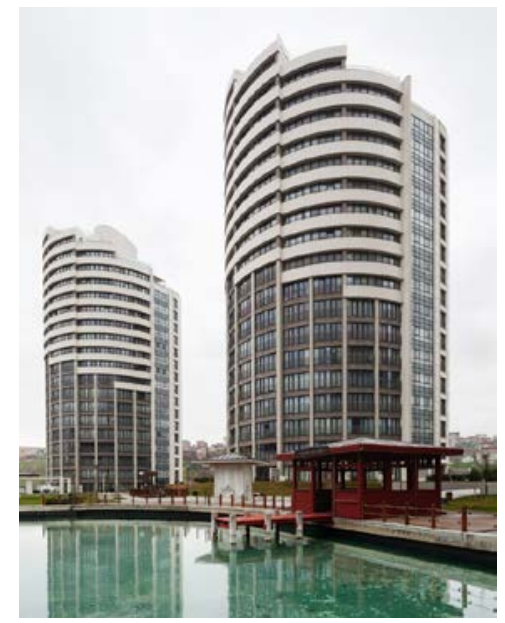

Şekil 7. Bosphorus City'de işlevi olmayan ve bağlamından kopuk bir vapur iskelesi (url-2)

Mimarlık üretiminde beğeni ve anlamın ortaya çıkış süreci giderek yapaylaşmaktadır. Belli ortamlarda ve tarihsel bağlamlarda üretilmiş, referans veren değerler, bağlamlarından kopartılarak stratejik bir şekilde bir araya getirilmekte, orijinalindeki üretilme biçiminden ve anlamından koparılarak yeniden üretilmektedir. Kitsch mimari nesnelerin içinde bulunduğu çevre ve bağlam ile bir diyalog kurduğundan söz edilemez.

\subsection{Sosyolojik bir olgu olarak 'kitsch': tüketim kültürü ve ideoloji}

Kitsch, hiç şüphesiz modernleşme sürecini izleyen sosyolojik bir gerçektir ve kitle kültürü, tüketim kültürü ve Adorno'nun ortaya koyduğu 'kültür endüstrisi' kavramı ile doğrudan ilişkilidir. Tüketim toplumunun yer değiştirmesiyle ortaya çıkan kitsch, piyasa düzeniyle sıkı bir ilişki içindedir. "Kitsch, nadir ve benzersiz nesnelere yeni değerler kazandırır, bu değer piyasa değeridir ve tüketimle ilgilidir" (Baudrillard, 1997 s. 124126). Calinescu (2010) kitsch ve piyasa düzeninin ilişkisini şöyle açıklamaktadır: "Kitsch teknik açıdan mümkün ve ekonomik açıdan karlı olur olmaz, her şeyin ucuz ya da pek o kadar ucuz olmayan taklitlerinin çoğaltılması piyasayla sınırlıdır. Değer doğrudan, özgün estetik anlamları eşsiz ve bu yüzden de taklit edilemez olmaktan kaynaklanan, ya da kaynaklanması gereken nesnelerin aldatıcı kopyalarına ya da reprodüksiyonlarına olan taleple ölçülmektedir" (Calinescu, 2010, s. 252).

Calinescu (2010), Tocqueville'den başlayarak, birçok toplum ve kültür eleştirmeninin, yaygın beğeni bozulmasının temel nedeni olarak statü arayışını gösterdiğini belirtir. Fakat kitsch olgusunun gücü, bir statü arayışı olmasında değil, daha ziyade insanların duygusal intiyaçlarına cevap vermesinde yatmaktadır. Calinescu'ya göre de kitsch'in 
yaygın ilgi görmesinin asıl sebebi sıkıcı gerçeklikten kaçma arzusudur: "Kitsch'in özünü oluşturan şey büyük olasılıkla onun açık uçlu belirlenemezliği, bulanık halüsinasyon gücü, aldatıcı düşselliği, kolay bir katharsis vaadidir" (Calinescu, 2010, s. 254).

Kundera (1986) ise kitsch'i daha aktif bir kültürel süreç olarak tanımlamaktadır: "varoluşla kesin olarak uzlaşmanın önerdiği estetik ülkü, bokun reddedildiği ve herkesin bok yokmuş gibi davrandığı bir dünyadır. Bu estetik ülkünün adı kitsch'dir. ... kitsch insan varoluşunda temelden kabul edilemez olan her şeyi kapsamı dışına atar" (Kundera, 1986, s. 256). Kitsch'in bu şekilde kavramsallaştırılması, kitsch estetiğinin istenmeyen ve hoşa gitmeyen problemleri, güvenli ve steril bir dünyayla maskelediğini anlatmaktadır. Benzer şekilde, Binkley de (2000) kitsch estetiğinin, stabil olmayan ve riskli bir dünyanın daha tanıdık, konforlu ve stabil bir dünyaya dönüştürülmesinin basit bir yolu olduğunu yazmaktadır (aktaran Atkinson, 2007, s. 525).

Broch'a göre (1969, s. 49) ise kitsch'in var olabilmesi, her şeyden önce kendi ruhunun aynası olarak gördüğü kitsch nesneye gereksinim duyan, kitsch'in tüketicisi olan bir öznenin varlığını gerektirir. İşte Calinescu'nun sıkıcı gerçeklikten kaçma arzusunda olan modern insanı, Broch'un tanımladığı bu kitsch tüketicisidir. Kitsch ve onun basit nostaljisi, süreksizlikler içeren modern dünyada, insanın daha güvenli hissetmesine yardım eder (Atkinson, 2007, s. 525).

Greenberg'e göre (1961, s. 9-11) kitsch, asla rastlantısal değildir; tam aksine kültür endüstrisi tarafından ideolojik olarak üretilmekte, büyük miktarlarda finansal olarak desteklenmekte ve karşılığında maksimum kâr hedeflenmektedir. Kitsch, kültür endüstrisi tarafından güdümlenmiştir. Adorno da (2003) kültür endüstrisinin kasıtlı olarak tüketiciyi kendine uydurduğunu, kültür endüstrisinin talep ettirdiğini ve halkın politik bir biçimde güdümlendiğini savunur. Üretim tarzının sadece belirli ürünleri değil aynı zamanda bu ürünlere yönelik intiyacı da yeniden ürettiğini dile getiren Adorno, sadece malların ya da hizmetlerin değil, tüketicilerin de kültür endüstrisinin birer ürünü haline geldiği savunur (aktaran Calinescu, 2010).

Kitsch olarak nitelendirilen nesnelerin de içinde bulunduğu tüketim sistemindeki değişimi Baudrillard (1997) ise şöyle açıklar: "tüketim ilkesinin haz olmadığının en iyi kanıtlarından biri, bugün hazzın bir zorlama olması ve hak ya da zevk olarak değil, yurttaşlık görevi olarak kurumsallaşmış olmasıdır" (Baudrillard, 1997, s. 85). Kitsch'in ortaya çıkışının, modern teknolojinin gelişimiyle (özellikle de sanat eserlerini çoğaltma tekniklerinin gelişimiyle) paralellik gösterdiğini belirten Calinescu (2010) bu açıdan bakıldığında modern zamanlardaki kitsch'in daha çok "ideolojik olarak yönlendirilmiş bir zevk yanılsaması" içerdiğini söyler. Bu yüzden kitle kültürü ya da kitsch, ideoloji veya sahte bilinç terimleriyle açıklanmaktadır.

Kitsch, dolayımsız tüketime yönelik estetik ürün yaratırken, tüketicinin gereksinimleri de kitle iletişim araçları ve medya aracılığıyla, piyasanın mantığı tarafından ideolojik olarak yönlendirilir. Bu güdümleme ya da yönlendirme, büyük topluluklar halinde malı kabul eden tüketicilerin önyargıları ve tutumları hakkında genelleştirilebilir bir önermeyi içerir (Calinescu, 2010, s. 266).

Bosphorus City örneğinde olduğu gibi, kitsch mimari nesneler, medya aracılığıyla tüketiciye seslenir ve tüketiciye Boğaz'da bir yalıda yaşama imkânını, Boğaz'ı seyretme fırsatını, bir yandan modern bir yandan geleneksel bir yaşamı, hayatın zevkini çoğaltmayı, dolayısıyla daha mutlu bir yaşamı ve iyi bir geleceği vaat eder. Bunları da İstanbul'un güzelliklerini veya geleneksel Türk evlerini yeniden inşa ederek yapacağını garanti eder. Projenin televizyon reklamlarında mutlu aileler eşliğinde "Hepimize 
Boğaz'da bir ev hepimize, mutlu bir ev hepimize... Ortaköy'den Boğaz'a açılma zamanı... Gelecek tam karşında, hayat bambaşka olacak, hayatın tadına varan binlerce mutlu aile..." gibi sloganlar yer alır. Geleneksel Türk evlerinin biçimsel özelliklerinin kopyalandığı konutlarda ise "eski Batı Anadolu, Türk Evi plan çözümleri ve İstanbul mimari ritimleriyle zengin bir yaşam kurgulandığı" ifade edilir.

Gazetelerde yer alan haberlerde de projenin niteliklerinden övgüyle bahsedilmiştir. 2011 yılında vatan gazetesinde yayınlanan haberde İnan, bu projenin gezdiği hiçbir projeye benzemediğini, hayal zenginliğinin çok fazla olduğunu yazmaktadır. Ayrıca bu projeden bir ev satın almakla sadece bir ev değil, Avrupa'da bile olmayan bir konsept satın alacağınızın altını çizmektedir. Boğaziçi yalısın penceresinden bakınca "insan kendini hakikaten Boğaziçi'nde hissediyor" diye de eklemektedir (İnan, 2011). Bunun dışında, görsel ve yazılı medyada projenin aldığı ödüller aracılığıyla da promosyonu yapılmıştır (url-10).

Kitle iletişim olanaklarının böylesine arttığı günümüzde kitsch'in yükselmesi doğaldır. Günümüzde beğenileri ve duygusal gereksinimleri, kitle iletişim araçları ve uzmanları tarafından ustalıkla yönlendirilen, büyük bir izleyici kitlesi ortaya çıkmıştır. Kitsch'in tüketim kültürü ve ideolojiyle ilişkisini Calinescu (2010), şöyle ortaya koyar: "Kitsch'in temel aldığı büyük psikolojik keşif, sanatsal kültürle doğrudan ya da dolaylı bağlantısı olan neredeyse her şeyin, sıradan mal gibi dolayımsız tüketime uygun bir şey haline getirilebileceği gerçeğinde yatar. ... Günümüz saplantılı tüketicisinin estetik taleplerine yanıt vermek üzere, kültür endüstrisi onun haz alabileceği her şeyi taklit etmekte, çoğaltmakta, yeniden üretmekte ve standartlaştırmaktadır” (Calinescu, 2010, s. 272).

\section{3. 'Kitsch' ve Estetik Deneyim}

Kitsch olgusunun tam anlamıyla kavranması, beğeni ve anlam boyutuyla bir estetik kategori, tüketim kültürü ve ideoloji ile olan ilişkisi çerçevesinde de bir sosyolojik kategori olarak anlaşılmasının yanı sıra, estetik deneyim ile kurduğu ilişkinin irdelenmesi önem kazanmaktadır. Kitsch mimari nesneler kullanıcısına, deneyimleyicisine nasıl bir estetik deneyim sunar?

Scruton (1979) duyusal ve zihinsel haz arasında bir ayırım yapar ve mimari hazzın düşünme sürecini içinde barındıran zihinsel bir haz olduğunu savunur. Scruton'a göre "estetik haz, sadece duyusal bir haz değildir, düşünme sürecini de içinde barındırır" (Scruton, 1979, s. 72). Ona göre, algılama, deneyim ve yorumlama birbirinden ayrılamaz. Duyu, deneyim ve yorumun birbirinden ayrılamaz olduğu bu tür algılamayı Scruton 'yaratıcı algılama' (imaginative perception) olarak ortaya koyar. 'Yaratıcı algılama' ve 'doğrudan algılama' (literal perception) farklıdır. Yaratıcı algılamada nesne anlam dünyası içinde algılanırken, doğrudan algılamada nesne saf haliyle algılanır (Scruton, 1979, s. 78).

Mimari deneyim yaratıcı algılamayı içerir ve deneyimin tamamlanabilmesi için gözlemcinin aktif katılımı gereklidir. Mimari deneyimin büyük bir kısmı yaratıcıdır ve böylelikle aynı zamanda estetik bir deneyimdir (Scruton, 1979, s. 96). Oysa ki kitsch, kendini sadece biçimsel olarak var ettiği ve bir anlam taşımadığı için, kitsch nesne diyalog içerisine gireceği birey ya da topluma iletmek istediği mesajı, onunla karşı karşıya geldiği ilk anda verir ve bundan sonra söyleyecek sözü yoktur. Kitsch, bırakmak istediği etkiyi sağlamak için her şeyi dile getirir ve söylenecek her şeyi söyler, kendini direkt ve açık olarak ortaya koyar. Kitsch, bir düşünme ve yorumlama sürecine yer bırakmadığından, bu durumda Scruton'ın düşünsel etkinlik aracılığıyla tanımladığı 
estetik deneyimin yaşanması zordur. Nesnenin mesajının son derece açık ve net olmasıyla, kitsch herhangi bir yorumlama etkinliğine ve hayal gücüne yer vermez. Bu yüzden gerçek bir estetik deneyim oluşturduğu söylenemez; kitsch ancak yüzeysel beğeniye hitap edebilir.

Kirshenblatt-Gimblett (1998), kitsch'in modern dünyada giderek daha güven verici bir olgu haline gelirken "eleştirel yargının terk edilmesini gerektirdiğini, çünkü bize ne düşünmemiz ve ne hissetmemiz gerektiğini söylediğini" belirtmektedir (aktaran Atkinson, s. 525). Harries de (1986) kitsch'in özünde monolojik bir yapısı olduğunu yazmaktadır; çünkü kitsch, nesne özne ile arasında eleştirel bir uzaklıktan yoksundur. Bu yüzden de kitsch, izleyicilerine sadece duygusal açıdan dokunabilir (aktaran Olivier, 2003, s. 108). Böylelikle kitsch, özne ile nesne arasındaki diyalog sürecini kısaltıp estetik deneyime olanak vermezken, monolojik yapısı ile eleştirel düşüncenin önünü kapatır. Postmodern kültürün kitsch'e bariz bir şekilde bağımlı olduğu günümüzde, objenin kendisinden hazcılığa doğru gerçekleşen kayma, kendini gösterdikleri bir anlam olmayan göstergeler şeklinde ortaya koyar ve bu da Baudrillard'ın (1996) hipergerçeklik ya da simülasyon kavramlarıyla açıklanabilir (Olivier, 2003, s. 107).

Baudrillard (1997, s. 126), "modellerin modeller aracılığıyla sürekli yeniden üretildiğini ve gerçekliğin ortadan kalktığını, bir şekilde otantik nesnenin yerine sürekli üretilen modellerin geçtiğini ve artık gerçekten daha gerçek gibi gözüken modellerin işlevinin sürekli bir simülasyon oluşturmak olduğunu" savunmaktadır. Ait olduğu gerçeklik ile bulunduğu gerçeklik arasında sahte ilişki kuran kitsch, tam da bu hiper-gerçek dünyanın nesnesidir. Bosphorus City projesi de bu açıdan bakıldığında Baudrillard'ın hiper-gerçeklik kavramını ve Eco'nun şu sözlerini örnekler gibidir: "Gerçek-sahtelerin (real-fakes) ve gerçeğinden daha gerçek görünen sahte şehirlerin evrenine giderek daha fazla dalıyoruz" (Eco, 1990, s. 14).

\section{DEĞERLENDIRME ve SONUÇ}

Bir estetik olgu olarak kitsch, algılanması kolay ve tanıdık yapısal formları, toplum belleğinde bir anlamı olan ve meşrulaşan öğeleri kullanıcıların beğenisine sunar ve biçim kurgusuyla kendini tanımlı kılarak, kitlelerin beğenisine hitap eder. Belli ortamlarda ve tarihsel bağlamlarda üretilmiş, referans veren değerleri bağlamlarından kopararak, yeniden üretir, taklit eder ve standartlaştırır.

Fakat kitsch, sadece beğeniyi ilgilendiren ve kötü zevk anlamına gelen masum bir kavram olarak algılanmamalıdır. Kitsch, piyasa düzeni tarafından güdümlenmiş ve ideolojik olarak yönlendirilmiştir. Tarihsel, yerel ve geleneksel değerleri kendi kullanma biçimi çerçevesinde ele alarak, medya aracılığıyla pazarlamakta ve farklı kimlik tanımlamaları oluşturmaktadır.

Tüketim kültürü ile piyasa tarafından yönlendirilen ve medya aracılığıyla da kitlelere empoze edilen kitsch'in bu denli popüler olmasındaki faktör, 'sunduğu katharsis vaadiyle', modern insanın sosyal ve psikolojik intiyaçlarına karşılık gelmesidir. Kitsch, stabil olmayan ve riskli bir dünyanın daha tanıdık, konforlu ve stabil bir dünyaya dönüştürülmesinin basit bir yolu olarak görülebilir.

Ticari başarı elde etmek adına bilinçli olarak geçmiş modelleri bağlamlarından kopararak kopyalayan ve içini boşaltarak birer imaj değerine indirgeyen kitsch, sahte bir gerçeklik, bir simülasyon veya hiper-gerçeklik durumu yaratır. Bu hiper-gerçeklik ya da simülasyon hayatın her alanında olduğu gibi mimarlıkta da gerçekliğin yerini 
almıştır. Hiper-gerçekliğin içinde yaşayan bireyler için eleştirel düşüncenin ve yaratıcı deneyimin önü giderek kapanır. Bir zihinsel sürece ve özne ile nesne arasında bir iletişim sürecine yer bırakmayan kitsch, bu açıdan bakıldığında gerçek bir estetik deneyim oluşturmakta yetersiz kalır, eleştirel yargının terk edilmesini gerektirir, çünkü insanlara ne düşünmeleri ve ne hissetmeleri gerektiğini söyler.

$\mathrm{Bu}$ aşamada, özne ile nesne arasındaki iletişimin ve estetik deneyimin sağlıklı olarak tekrar kurulmasında belki de otantiklik kavramını yeniden gündeme getirmek yararlı olabilir. Heidegger'e göre "otantiklik kamusal alana emilip onun çeşitli kalıplarında körü körüne gözden kaybolmak yerine, ayırt edici bir biçimde kendisine ait bir varoluş biçimi arar" (aktaran Makkreel, 2010, s. 320). Yani onun felsefesinde otantiklik, bilinçli öznenin dış etkenlerin baskısına göre hareket ettiği ve değiştiği, hareket dürtüsünün dış etkenler tarafından empoze edilmeyip öznenin kendisinden kaynaklandığı bir yöntemdir. Bu da kitsch'in tam tersi yönünde bir mimari ve sanatsal üretime işaret etmektedir. Bu bağlamda, güncel mimari ve kentsel üretimlerde, otantiklik, özgünlük, eleştirel mesafe gibi estetik deneyime dair kavramların daha çok gündeme getirilmesi ve derinlemesine tartışılmasının, daha nitelikli çevrelerin yaratılması için önemli açıımlar sağlayacağı açıktır.

\section{KAYNAKLAR}

Adorno, Theodor W., "Kültür Endüstrisini Yeniden Düşünürken”, Çev.: B. O. Doğan, Cogito, sayı 36, Y.K.Y. Yayınları, İstanbul 2003, s. 76-83.

Atkinson, David, "Kitsch Geographies and Everyday Spaces of Social Memory", Environment and Planning A, vol. 39, issue.3, 2007, s. $521-540$.

Baudrillard, Jean, Tüketim Toplumu: Söylenceleri/Yapıları, (Çev.: F. Keskin ve H. Deliçaylı), Ayrıntı Yayınları, İstanbul 1997.

Broch, Hermann, "Notes on the Problem of Kitsch", Kitsch: An anthology of bad taste, (Ed.: Gillo Dorfles), Studio Visto London, London 1969, s. 49-76.

Calinescu, Matei, Modernliğin Beş Yüzü: Modernizm, Avangard, Dekadans, Kitsch, Postmodernizm, (Çev.: S. Gürses), Küre Yayınları, İstanbul 2010.

Colquhoun, Alan, "Postmodernizm and Structuralism: A Retrospective Glance", Assemblage, no. 5, 1998, s. 6-15.

Dorfles, Gillo, Kitsch: An anthology of bad taste, Studio Visto London, London 1969.

Eco, Umberto, Travels in Hyperreality, (Çev.: W. Weaver), Harvest, New York 1990.

Greenberg, Clement, Art and Culture: Critical Essays, 1st printing, Beacon Press, Boston 1961.

İnan, E. (2011, 24 Nisan). Maketti artık gerçek oldu insan gezerken etkileniyor. Vatan Gazetesi. <http://www.gazetevatan.com/ercan-inan-373000-yazar-yazisi-maketti-artikgercek-oldu-insan-gezerken-etkileniyor/>, erişim tarihi 02.06.2020.

Kulka, Thomas, Kitsch and Art, 2nd printing, The Pennsylvannia University Press, Pennsylvannia 2002. 
Kundera, Milan, Varolmanın Dayanılmaz Hafifliği, (Çev.: F. Özgüven), İletişim Yayınları, İstanbul, 1986.

Makkreel, Rudolf A. "Otantik Yorumdan Otantik İfşaaya Doğru: Kant ile Heidegger Arasındaki Mesafeyi Aşmak", Heidegger, (Ed.: Aktok, Özgür ve Bal, Metin), Doğu Batı Yayınları, Ankara 2010, s. 309-332.

Olivier, Bert, "Kitsch and Contemporary Culture", South African Journal of Art History, vol. 18, 2003, s. 104-112.

Rapoport, Amos, The Meaning of the Built Environment: A Nonverbal Communication Approach, The University of Arizona Press, Tuscon 1990.

Scruton, Roger, The Aesthetics of Architecture, 2nd printing, Princeton University Press, Princeton 1980.

Tanyeli, Uğur, "Aslolan 'Kitsch'tir”, Arredamento Dekorasyon, sayı. 21, Aralık 1990, s. 103-108.

url-1 <https://bosphoruscity.wordpress.com/2012/08/29/bosphoruscity-de-ayricalikli-biryasam/>, erişim tarihi 24.06.2020.

url-2 <http://www.evrenolarchitects.com/projeler-Bosphorus_City-4.html>, erişim tarihi 24.06.2020.

url-3 <http://www.mimarizm.com/makale/bosphorus-city-adi-beni-birinci-gundenrahatsiz-etti_115669>, erişim tarihi 14.06.2020.

url-4 <http://blog.aysefugenarda.com.tr/2017/08/09/sadullah-pasa-yalisinin-huzunluhikayeleri/>, erişim tarihi 02.07.2020.

url-5

<https://commons.wikimedia.org/wiki/File:Bosphorus_Bridge,_\%C4\%B0stanbul_(1308 0301674).jpg>, erişim tarihi: 02.07.2020.

url-6 <http://www.arkiv.com.tr/proje/bosphorus-city/1024>, erişim tarihi 24.06.2020.

url-7 <https://commons.wikimedia.org/wiki/File:Kanlica.JPG>, erişim tarihi 02.07.2020.

url-8

$<$ https://commons.wikimedia.org/wiki/File:Zarif_Mustafa_Pa\%C5\%9Fa_Yal\%C4\%B1s \%C4\%B1_in_Kanl\%C4\%B1ca_on_the_Bosphorus,_Turkey_002.jpg>, erişim tarihi 02.07.2020.

url-9 <http://wowturkey.com/t.php?p=/tr278/serkan33_bogaz.jpg>, erişim tarihi 24.06.2020.

url-10 <https://www.sozcu.com.tr/emlak/bosphorus-city-mipimde-en-iyi-turk-projesisecildi.html>, erişim tarihi: 02.06.2020. 